\title{
Banheiro ecológico uma alternativa sustentável para comunidades no interior da Amazônia
}

O banheiro ecológico surge como alternativa de saneamento descentralizado, e este artigo propõe descrever a experiência de banheiros secos como uma alternativa sustentável para as comunidades no interior da Amazônia. Para desenvolver esse estudo, foi escolhida como lócus da investigação a comunidade Alter do Chão, no município de Santarém (PA). A seleção dos sujeitos das entrevistas aconteceu a partir da identificação de pontos onde há construção dos banheiros ecológicos, com o intuito de discutir os princípios defendidos pelas tecnologias implantadas na sua construção e quais os benefícios e dificuldades dessa construção apontando suas características, vantagens e desvantagens. Os banheiros secos apresentam um caráter tecnológico de fácil manejo e baixo custo de operação e construção. Portanto, entende-se que essa técnica é a melhor solução sanitária a ser construída nessas regiões.

Palavras-chave: Saneamento; Sustentabilidade; Amazônia.

\section{Ecological toilet a sustainable alternative for communities in the interior of the Amazon}

The ecological toilet emerges as an alternative to decentralized sanitation, and this article proposes to describe the experience of dry toilets as a sustainable alternative for communities in the interior of the Amazon. To develop this study, the Alter do Chão community was chosen as the research locus in the municipality of Santarém (PA). The selection of the interview subjects took place from the identification of points where there is construction of ecological bathrooms, in order to discuss the principles defended by the technologies implemented in its construction and what are the benefits and difficulties of this construction, pointing out its characteristics, advantages and disadvantages. Dry toilets have a user-friendly technological character and low operating and construction costs. Therefore, it is understood that this technique is the best sanitary solution to be built in these regions.

Keywords: Sanitation; Sustainability; Amazon.

Topic: Desenvolvimento, Sustentabilidade e Meio Ambiente Reviewed anonymously in the process of blind peer.
Received: 01/06/2019

Approved: 03/08/2019
Alex Bruno Cunha Castro

Universidade Federal do Oeste do Pará, Brasil http://lattes.cnpq.br/9901614137339518

alexbruno_xp@hotmail.com

Sâmia Rubielle Silva de Castro

Universidade Federal do Oeste do Pará, Brasil

http://lattes.cnpq.br/5857151126212299

samiarubiellee@hotmail.com
Referencing this:

CASTRO, A. B. C.; CASTRO, S. R. S.. Banheiro ecológico uma alternativa sustentável para comunidades no interior da Amazônia. Nature and Conservation, v.12, n.2, p.1-10, 2019. DOI:

http://doi.org/10.6008/CBPC2318-2881.2019.002.0001 


\section{INTRODUÇÃO}

Segundo o Trata Brasil (2012) o saneamento básico é o conjunto de medidas que visa preservar ou modificar as condições do meio ambiente com a finalidade de prevenir doenças e promover a saúde, melhorar a qualidade de vida da população, a produtividade do indivíduo e facilitar a atividade econômica. Andregheto (2010) destaca que 13 milhões de brasileiros não têm acesso a banheiro no domicílio, e 20 mil óbitos anuais são registrados em decorrência de doenças diarreicas que são responsáveis por mais da metade dos gastos públicos com saúde no Brasil. Suas causas estão relacionadas às condições inadequadas de saneamento básico. Entretanto, como aponta Ribeiro et al. (2002) o saneamento ambiental não tem sido historicamente priorizado, seja na formulação de políticas públicas, ou nas ações do setor privado da economia, resultando em condições insatisfatórias, que decorrem da sua insuficiência ou deficiência.

Na Amazônia, este desafio é ainda mais sério. De um lado, existe um problema estrutural: o pequeno apoio dado às instituições de ciência, tecnologia e inovação da região. De outro, destaca-se a complexidade de uma região que abriga uma enorme diversidade social, econômica, étnica, cultural, biológica e física. Preservar o meio ambiente e ainda garantir o desenvolvimento este é o objetivo de todas as ações que garantam a sustentabilidade ambiental.

Por exemplo, Mueller (2007) compreende que o desenvolvimento sustentável está atrelado ao crescimento econômico: o capital físico com relações demográficas e desenvolvimento tecnológico das organizações, tanto com respeito à biodiversidade, quanto a forma de trabalhos ministrados por estas. É necessário constatar que de acordo com o RECESA (2008), atualmente, a fonte principal de poluição nos corpos hídricos é proveniente do esgoto sanitário doméstico.

Segundo o LEED (2008), como solução para esse problema, muitas tecnologias vêm sendo desenvolvidas no mundo para diminuir a contaminação da população e o consumo de água no sistema convencional de saneamento básico, que utilizam de modelos hidráulicos. Uma destas alternativas é o banheiro seco que é uma bioconstrução que não necessita de água.

É usada matéria orgânica seca, serragem, folhas secas, folhas picadas, palhas, casca de café, palha de milho moída, palha de arroz ou palha do feijão para cobrir as fezes e a urina. É uma tecnologia utilizada em diversas partes do mundo, como EUA, Canadá, Suécia, Noruega, Nova Zelândia, Austrália e Inglaterra. De fato, os banheiros secos vêm sendo tratados como uma das alternativas para o problema da poluição da água de maior potencial.

O Conselho Norte-Americano de construções ecológicas (US Green Building Concil - USGBC) estabelece que o banheiro seco como uma das tecnologias de maior potencial, atualmente. Seu mecanismo consiste da utilização do resíduo sanitário para o processo de compostagem e transformação do resíduo em húmus, através da síntese de microrganismos e consequente higienização do composto. O resíduo sanitário é formado por dejetos humanos, fezes e urina, papel higiênico, e material orgânico, como cinzas e serragem, para equilíbrio químico do composto. Existem diversos modelos de banheiros secos, porém se diferenciam basicamente entre separadores de urina ou não (ALVES, 2009; JENKIS, 2005). 
Portanto é uma das tecnologias mais eficazes em evitar a poluição ambiental por águas residuais, e assim conservar os recursos hídricos como um todo. Segundo Alves (2009), apesar das inúmeras variações de modelos, materiais e fabricantes, o banheiro seco consiste basicamente de: uma tampa de privada conectada a um suporte; e acoplada a um balde (coletor), que quando preenchido, deverá ser retirado e ter seu conteúdo despejado em um local para o processo de compostagem.

Souza et al. (2009) destaca que a relevância desse conceito consiste em direcionar os projetos realizados sobre bases comunitárias para possibilitarem a participação social na busca por soluções que visem à modificação de determinada realidade. Assim, o desenvolvimento de projetos relativos à promoção de saúde deve priorizar a utilização dos recursos naturais e sociais comunitários sustentavelmente. É necessário que as comunidades saibam identificar suas aspirações e necessidades para modificarem favoravelmente o ambiente em que vivem.

Amatuzi et al. (2013) aponta que um dos benefícios da implantação de um banheiro seco é o fato de quase não necessitar de água para nenhuma parte do processo. Ele também dá aos dejetos uma utilidade, pois o mesmo passa por uma etapa de transformação, tendo como produto final um adubo $100 \%$ orgânico, que se dá a partir de um aquecimento dos insumos podendo chegar até $60^{\circ} \mathrm{C}$, eliminando, assim, os agentes patológicos, dando possiblidade de ser utilizado em plantações e não levando contaminação ao solo e os lençóis freáticos. Devido ao pouco consumo da água, esta alternativa se mostra sustentável e ecológica, trazendo consigo a simplicidade, que ocasiona o baixo custo para a construção de um banheiro seco. A partir de uma simples estrutura, é possível separar a urina das fezes, para que o odor não exista.

De acordo com Alencar (2009), nas áreas urbanas, os principais fatores que dificultam a aceitabilidade dos banheiros secos estão relacionados à estrutura imobiliária já consolidada, à falta de informação em relação à tecnologia, e à falta de espaços adequados para a disposição do composto produzido. Nas áreas rurais, o maior empecilho é a falta de informações sobre a tecnologia.

De acordo com Dagnino (2004; 2009), a utilização de tecnologias sociais pode representar significativo desenvolvimento social haja vista a possibilidade de acesso, sobretudo para as classes sociais com menor poder aquisitivo, a serviços não prestados pelo poder público. Porém, a prática de transferência tecnológica ainda enfrenta diversos desafios, dentre os quais as questões culturais são os mais significativos.

Por cultura entende-se o conceito definido por Eagleton (2005). Para Eagleton (2005), a cultura representa os costumes e as práticas que identificam modos de vida determinados, do pensar ao agir, caracterizando determinada sociedade. É entendida enquanto processo de construção social, o qual sofre modificações ao longo do tempo, mas contribui para a reprodução de determinadas práticas. Os elementos culturais mais significativos são a educação, a economia e a política.

Diante disso, o banheiro ecológico surge como alternativa de saneamento descentralizado, e este artigo propõe descrever a experiência banheiros secos como uma alternativa sustentável para as comunidades no interior da Amazônia, apontando suas características, vantagens e desvantagens e a percepção das pessoas que usam e construíram essa tecnologia sustentável. 


\section{METODOLOGIA}

Tomando como ponto de partida o objetivo desta pesquisa, que é analisar e descrever o banheiro seco como solução sustentável no interior da Amazônia, apontando suas características, vantagens e desvantagens e a percepção das pessoas que usam e implantaram essa tecnologia sustentável, foi adotado o método de pesquisa qualitativa, de caráter exploratório, que consideramos o mais apropriado para o tipo de análise que pretendemos fazer. Antes, porém, cabe-nos contextualizar o tipo de pesquisa escolhido para um melhor entendimento a respeito.

Quanto aos fins, o tipo de investigação escolhido para a realização da pesquisa qualitativa enquadrase como exploratória. Segundo Vergara (2009), ela "é realizada em áreas na qual há pouco conhecimento acumulado e sistematizado. Por sua natureza de sondagem, não comporta hipóteses que, todavia, poderão surgir durante ou ao final da pesquisa". No que diz respeito aos meios de investigação, optamos pela pesquisa de campo, que, também de acordo com Vergara a investigação empírica realizada no local onde ocorre ou ocorreu um fenômeno ou que dispõe de elementos para explicá-lo. Pode incluir entrevistas, aplicação de questionários, testes e observação participante ou não.

Em relação aos procedimentos qualitativos, segundo Creswell (2007), eles se baseiam em dados de texto e imagem, que têm passos únicos na análise de dados e usam estratégias diversas de investigação. 0 pesquisador vai ao local onde está o entrevistado para conduzir a pesquisa, permitindo envolvimento do pesquisador nas experiências dos participantes ou entrevistados. A pesquisa qualitativa é interpretativa, e o pesquisador se envolve de forma intensa com os entrevistados.

Para desenvolver esse estudo, foi escolhida, como lócus da investigação, a comunidade Alter do Chão (latitude: -2.5043 e longitude: -54.9546), que é um dos distritos administrativos do município de Santarém, no estado do Pará. Localizado na margem direita do Rio Tapajós, distante do centro da cidade acerca de 37 quilômetros através da rodovia Everaldo Martins (PA-457). A seleção dos sujeitos das entrevistas aconteceu a partir da identificação de pontos onde há construção dos banheiros secos, com o intuito de discutirmos os princípios defendidos pelas tecnologias implantadas na sua construção quais os benefícios e dificuldades dessa construção.

A principal fonte da coleta de dados para a análise deste estudo foram as entrevistas realizadas com pessoas que realizam construções de forma sustentáveis, questionando-os quanto à percepção da conservação do meio ambiente. Optando por realizar a entrevista por pauta, semiestruturada, utilizando um roteiro de perguntas abertas, flexíveis tanto para o entrevistado quanto para o entrevistador, foram oito questões apresentadas aos sujeitos da entrevista relacionadas com a temática.

Com relação ao conteúdo das perguntas os entrevistados foram questionados sobre as técnicas usadas para a bioconstrução do banheiro seco, descrevendo seus pontos positivos e negativos, e de como surgiu o interesse em trabalhar essas técnicas de bioconstrução, bem como se houve algum treinamento, de que forma o trabalho realizado é divulgado, qual a importância do mesmo para a região e se há algum apoio da prefeitura, ONGs ou empresas. 
Após o término do preenchimento dos questionários, os instrumentos foram devolvidos e identificados por ordem de devolução através de um código para garantir o anonimato. Exemplo: E1 (E1 = Entrevistado que primeiro respondeu o questionário). Da mesma forma se deu com os demais. Como optamos por um tipo de pesquisa qualitativa, escolhemos tratar os dados de forma não estatística. Na análise dos resultados, tem-se a exposição desses dados com as respectivas discussões teóricas.

\section{RESULTADOS E DISCUSSÃO}

Na tabela 1, temos as principais respostas dos participantes em relação às vantagens e desvantagens do banheiro seco. A partir dos dados, percebemos que as respostas dos participantes apontaram algumas vantagens e desvantagens da implantação do banheiro seco. Dentre eles, ficou evidente que essa tecnologia trás diversos benefícios nessas regiões do interior da Amazônia, como podemos perceber na resposta do entrevistado E2, que nos disse que 'os benefícios do banheiro seco são inúmeros. O adubo, usei para transformar o jardim da minha casa em fértil. Na minha casa é assim, outro dia colhi um cacho de banana da bananeira que eu plantei bem pequeninha e cresceu devido ao adubo que foi produzido por mim' (entrevistado E2).

Tabela 1: Vantagens e Desvantagens do Sistema de Banheiro Seco.

\begin{tabular}{|l|l|}
\hline Vantagens & Desvantagens \\
\hline Economia de água e dinheiro & Grande barreira cultural para aceitação \\
\hline Tecnologia simples & Necessita adição/fonte de material orgânico seco \\
\hline $\begin{array}{l}\text { Evita o gasto com construção de tubulações ligada a redes de } \\
\text { esgoto }\end{array}$ & Requer capacitação para seu uso \\
\hline O risco de contaminação aquífera é minimizado & $\begin{array}{l}\text { Processo de compostagem requer tempo e } \\
\text { conhecimento }\end{array}$ \\
\hline Sistema de saneamento alternativo e ecológico & \\
\hline
\end{tabular}

Segundo Verdejo (2010), as condições socioeconômicas também atuam como fator limitante. Mesmo entre comunidades carentes, as tecnologias sociais podem ser percebidas como retrocesso face à hegemonia exercida pelas tecnologias convencionais. Nesse sentido, é necessário esclarecer as comunidades sobre as vantagens e desvantagens de determinada tecnologia para que seja despertado o interesse em participar das atividades propostas, pois a participação social pode ensejar mudanças de hábitos entre os moradores, mas que nem sempre são aceitas.

Alves (2009) ressalta que modelo de banheiro seco parte de um preceito básico, a não utilização de água na sua operação. Portanto é uma das tecnologias mais eficazes em evitar a poluição ambiental por águas residuais, e assim conservar os recursos hídricos como um todo. Apesar das inúmeras variações de modelos, materiais e fabricantes, o banheiro seco consiste basicamente de: uma tampa de privada conectada a um suporte e acoplada a um balde (coletor) que quando preenchido deverá ser retirado e ter seu conteúdo despejado em um local para o processo de compostagem.

Segundo Jenkins (2005), é minimamente irônico observar como o homem tem tratado, ou não, o problema da geração e manejo do seu próprio resíduo. Uma questão ambiental que vem perseguindo nossa espécie desde seus primórdios, e permanecerá até nossa extinção. Além das barreiras culturais, também é preciso vencer o lobby das grandes corporações na produção de fertilizantes artificiais para o ciclo da 
agricultura e a falta de conhecimento técnico no reciclo de dejetos humanos. A figura 1 mostra o adubo orgânico utilizado para nascer um jardim fértil.

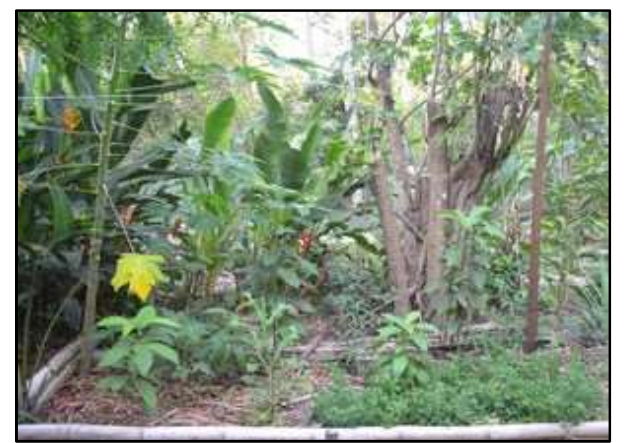

Figura 1: Adubo orgânico utilizado no jardim.

Segundo o entrevistado E4 o banheiro seco foi construído e utilizado durante o Festival das Águas evento que foi realizado de 11 a 15 de novembro de 2016 e debateu a importância da água para o planeta. A figura 2 mostra a construção do banheiro seco construído para o festival das águas. Concordando com esse pensamento, Breslin (2001) que reafirma a necessidade da participação da comunidade em todas as fases do processo de escolha do modelo de saneamento a ser escolhido e o seu planejamento. Breslin (2001) enfatiza a relevância dos aspectos culturais bem como a contínua monitoria para assegurar a manutenção do sistema e do uso correto do mesmo.

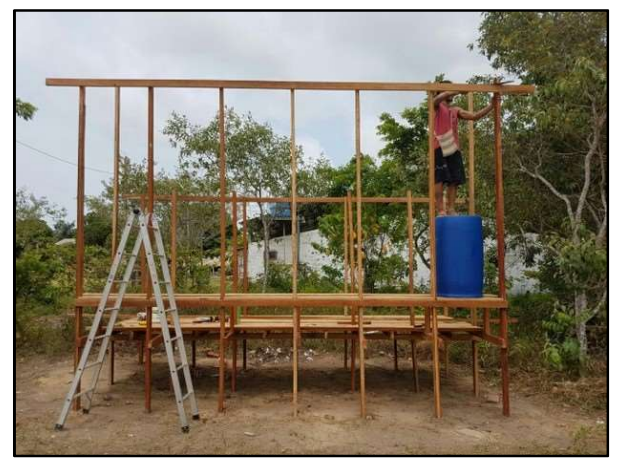

Figura 2: Estrutura do banheiro seco utilizado no festival das águas.

O banheiro seco com recipientes móveis possui estrutura simples. É constituído por um recipiente móvel para as excretas fixado logo abaixo do assento sanitário, sendo possível realizar sua remoção após atingir sua capacidade. Apesar do seu baixo custo de implantação, o sistema com recipientes móveis não constitui um sanitário compostável, já que as excretas dispostas no recipiente devem ser levadas para local apropriado para sua disposição. $\mathrm{O}$ entrevistado E4 nos afirmou que 'a área necessária para construção dos banheiros secos não demanda grande espaço. Por sua simplicidade, podem ser instalados em pequenas áreas junto à residência ou afastados dela' (Entrevistado E4).

A construção dos banheiros secos não representa complexidade, pois envolve as mesmas técnicas e processos utilizados na construção civil. Assim, dispensa mão-de-obra especializada, podendo ser empregadas pessoas ou membros das residências, ou comunidades onde os banheiros serão instalados. Para 
que essas pessoas sejam empregadas na construção dos banheiros secos, é necessária a realização de instruções quanto à tecnologia: o que é; vantagens; técnicas de construção; e forma correta de utilização.

Segundo Sá (2011) a implantação de banheiros secos compostáveis em áreas onde não existe coleta de esgoto, principalmente zonas rurais, se apresenta como uma alternativa simples, de baixo custo e que não agride o meio ambiente. O sanitário compostável não utiliza água, os dejetos ficam armazenados em uma câmara e passam por um processo de compostagem. O composto obtido pode ser usado em jardins, ou como recurso agrícola. Esta alternativa respeita o ciclo natural dos elementos, contribui para a redução do consumo de água, e evita a contaminação desta por dejetos humanos.

Para que a compostagem ocorra de forma eficiente e o sistema não produza odores, é necessário que o material fecal seja coberto por areia fina, serragem ou cinzas secas logo após a utilização dos sanitários pelos usuários, pois o processo de compostagem é promovido por microrganismos aeróbios que transformam a matéria orgânica depositada nas câmaras em matéria orgânica estabilizada. De acordo com Berger (2007), o composto orgânico produzido nos banheiros secos, o material húmico formado a partir das excretas humanas pode ser utilizado como adubo para o solo, favorecendo maior absorção de nutrientes pelas culturas agrícolas. A figura 3 mostra o material utilizado no caso à serragem utilizada no processo.

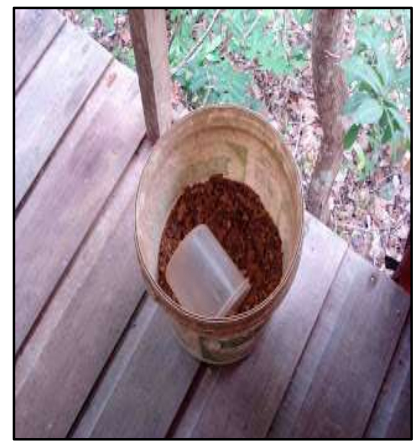

Figura 3: Serragem utilizada no processo de funcionamento do banheiro.

De acordo com Peasey (2000), o uso incorreto do banheiro seco ou outros problemas operacionais podem aumentar a sobrevivência de patógenos e levar a um aumento no risco de transmissão de doenças, tanto para os que manipulam o material com as excretas supostamente tratadas, quanto para consumidores de safras fertilizadas com os produtos finais dos banheiros secos.

\begin{abstract}
A operação e manutenção dos banheiros secos podem ser consideradas procedimentos simples. Para a operação, é necessário que o usuário conheça o funcionamento do banheiro seco, e reconheça a importância da tecnologia. A manutenção é a etapa que exige boa vontade do usuário. O maior esforço na etapa de manutenção ocorre durante a limpeza ou esvaziamento das câmaras de compostagem, as quais devem ser esvaziadas, limpas, e novamente lacradas para evitar a entrada de vetores e insetos.
\end{abstract}

Os entrevistados foram questionados a respeito da forma de uso do banheiro seco, conforme o entrevistado E2 relatou é importante que durante o uso do banheiro seco sigam-se algumas recomendações de funcionamento, evitando maus odores e contribuindo para a compostagem, no qual se destacam a separação de urina e adição de serragem. De acordo com Austin (2007), a limpeza do banheiro é essencial para a higiene e deve ser feita na mesma intensidade de um banheiro convencional. Na figura 4, há as instruções de uso do banheiro seco. 


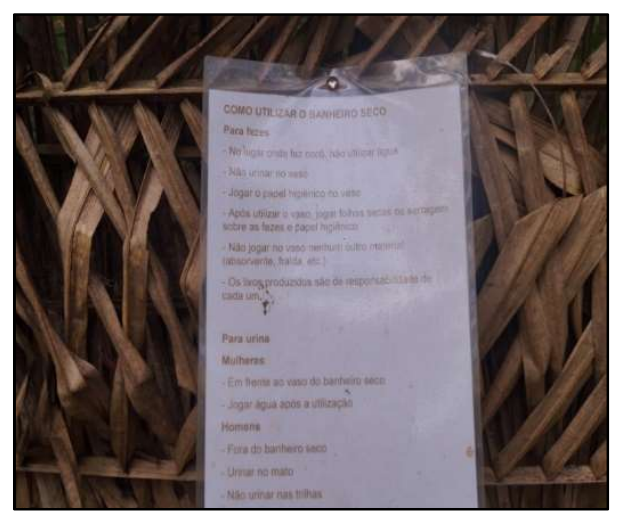

Figura 4: Instruções para utilizar o banheiro seco.

Durante a organização e execução do projeto para implantação do banheiro seco em uma comunidade no interior da Amazônia, foram considerados diversos aspectos, dentre os quais os modos de vida, as condições sanitárias de cada comunidade, e os aspectos técnicos de cada alternativa de banheiro seco. Os materiais utilizados e os custos para a construção da estrutura geral dos banheiros secos variam de acordo com os recursos disponíveis no nível local.

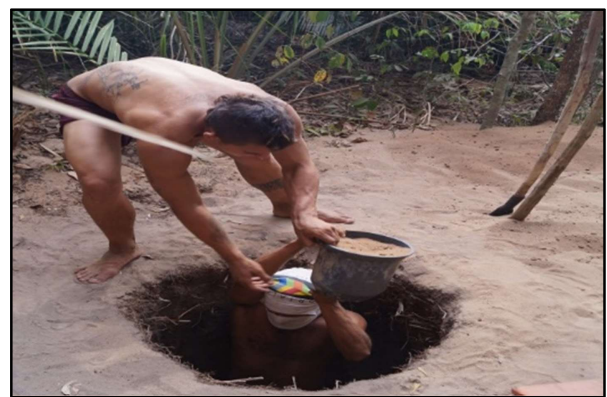

Figura 5: Construção do banheiro seco.

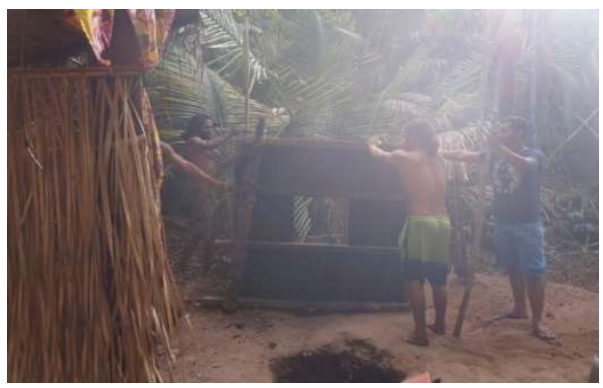

Figura 7: Fase final da construção do banheiro seco.

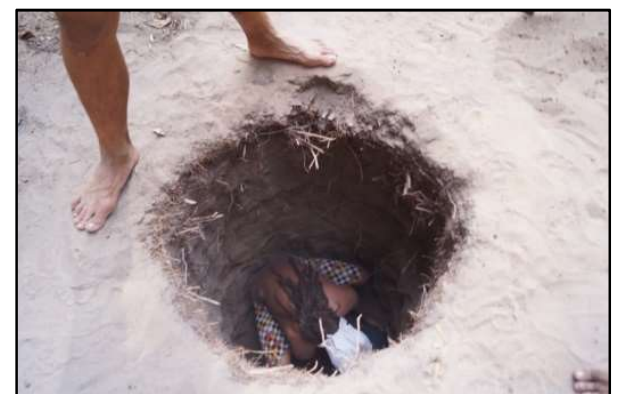

Figura 6: Construção do banheiro seco.

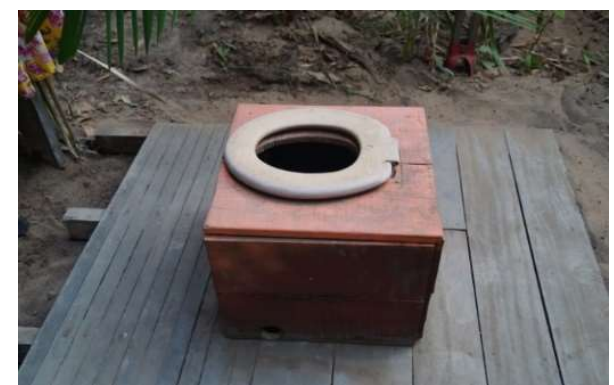

Figura 8: Banheiro seco construído, faltando somente as paredes.

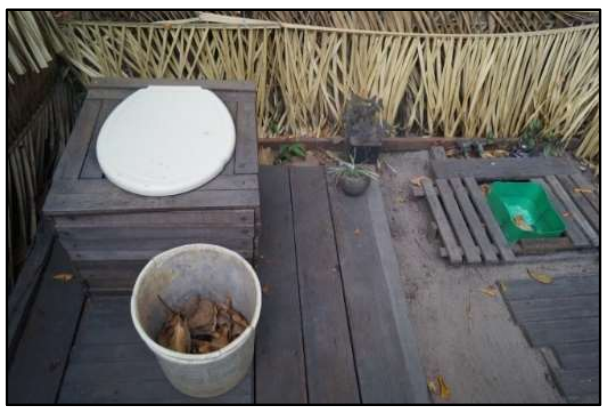

Figura 9: Banheiro seco. 
Segundo Peasey (2000), normalmente, são construídos pela comunidade com materiais locais ou são pré-fabricados. Austin (2007) ressalta que estrutura pode ser toda construída acima do nível do solo, incluindo os recipientes de armazenamento de fezes e urina, aproveitando-se o desnível do terreno. Caso a área seja plana, pode ser construída uma pequena escada para elevar o nível do vaso sanitário e permitir a troca dos recipientes com fezes e urina, ou no caso de as câmaras fixas realizarem a raspagem do composto. Outra opção é um buraco raso com cerca de $50 \mathrm{~cm}$ de profundidade para evitar a necessidade da escada. A construção da estrutura geral deve assegurar resistência frente aos efeitos climáticos, durabilidade, conforto térmico (materiais isolantes) e boa ventilação. As figuras 5 a 9 ilustram a construção do banheiro seco em uma comunidade na Amazônia.

Segundo o entrevistado E4, os custos de implantação dos banheiros secos variam de acordo com o método, os materiais empregados para construção, e os seus valores em cada localidade. Podemos concluir que mesmo com a variação de valores existente, a implantação de banheiros compostáveis implica em menores gastos, quando comparada às soluções convencionais para tratamento de esgotos sanitários, pois dispensam a construção de estruturas complexas para o seu funcionamento.

Ainda assim, os banheiros secos são tecnologia acessível a grande parcela da população. Seus custos de construção, instalação, operação e manutenção podem ser adequados a cada localidade. O uso de materiais alternativos pode reduzir o valor necessário para sua construção. Por isso, os projetos dos banheiros secos devem ser adequados para a realidade socioeconômica de cada localidade. A partir desta avaliação, conclui-se que o banheiro seco surge como alternativa de saneamento descentralizado, como uma alternativa sustentável para as comunidades no interior da Amazônia. De acordo com Botto (2005), essas ações são fundamentais para a promoção da viabilidade social no que se refere à difusão dos banheiros secos

\section{CONCLUSÕES}

Este estudo uma alternativa viável nos pontos de vista econômico, cultural, operacional e tecnológico, para a problemática do saneamento básico encontrada no interior da Amazônia. Entende-se que projetos na área de Engenharia Social deveriam ser mais estimulados e validados dentro do âmbito acadêmico, uma vez que propostas nessa esfera são essenciais para o desenvolvimento de uma sociedade mais justa e igualitária. Enquanto os indivíduos mais abastados, em geral, dispõem de um sistema de coleta de esgoto sanitário, as populações menos favorecidas são mais impactadas pela ineficiência do Estado em prover inúmeros serviços básicos, entre os quais o fornecimento de água e a coleta de esgoto. Os banheiros secos se apresentam como uma das alternativas mais promissoras no tratamento dos dejetos humanos, a partir da coleta dos resíduos em recipientes e síntese final no processo de compostagem.

Além de possuírem as características supracitadas, como baixo consumo de água e diminuição da contaminação, os banheiros secos apresentam um caráter tecnológico de fácil manejo e baixo custo de operação e implantação. Portanto, entende-se que essa técnica é a melhor solução sanitária a ser construída nessas regiões. 


\section{REFERÊNCIAS}

ALENCAR, M. H. B. C.. Viabilidade técnica e social do tratamento alternativo de resíduos humanos como forma de promoção da saúde e da qualidade ambiental na comunidade Coquilho, zona rural de São Luís-MA. Dissertação (Mestrado em Saúde e Ambiente) - Universidade Federal do Maranhão, São Luís, 2009.

ALVES, B. S. Q.. Banheiro seco: Análise da eficiência de protótipos em funcionamento. Monografia (Graduação em Ciências Biológicas) - Universidade Federal de Santa Catarina, Florianópolis, 2009.

AMATUZI, B.; BOTEGA, J. L.; CELANTE, L. S.. Implementação de banheiro seco como proposta de saneamento ecológica. Monografia (Graduação em Engenharia Ambiental) Universidade Federal do Rio de Janeiro, Rio de Janeiro, 2013.

ANDREGHETO, P.. Saneamento Básico: urgência sem pressa. Brasil Sustentável, v.31, p.21-27, 2010.

AUSTIN, L. M.. Design and operation criteria for urine: diversion ecological sanitation systems with particular reference to public health. Pretória: University of Pretoria, 2007.

BERGER, W.. Composting toilet systems in practice: examples and developments in private houses, multi-storey houses and public facilities in Germany during the last 20 years. In: INTERNATIONAL CONFERENCE ON SUSTAINABLE SANITATION. Anais. Pequim: 2007.

BOTTO, M.. Estudo da viabilidade técnica e social de tecnologias alternativas de saneamento em comunidades no Estado do Ceará. In: CONGRESSO BRASILEIRO DE ENGENHARIA SANITÁRIA E AMBIENTAL, 23. Anais. Fortaleza: 2005.

BRESLIN, E. D.. Introducing Ecological Sanitation: Some Lessons from a Small Town Pilot Project in Moçambique. Rockville Pike: 2001.

CRESWELL, J. W.. Projeto de pesquisa: métodos qualitativos, quantitativos e misto. 2 ed. Porto Alegre: Artmed, 2007.

DAGNINO, R. P.. A tecnologia social e seus desafios. Rio de Janeiro: FBB, 2004.
DAGNINO, R. P.. Tecnologia social: ferramenta para construir outra sociedade. Campinas: UNICAMP, 2009.

EAGLETON, T.. A ideia de cultura. São Paulo: EDUNESP, 2005.

JENKIS, J. The humanure Handbook: a guide to composting human manure. Grove City: 2005.

LEED. Leardship in Energy and Environmental Design. LEED 2009 for New Construction and Major Renovations Rating System USGBC. São Paulo: LEED, 2009.

MUELLER, C.. Os Economistas e as relações entre o sistema econômico e o meio ambiente. Brasília: UNB, 2007.

PEASEY, A.. Health Aspects of Dry Sanitation with Waste Reuse. London: Water and Environmental Health, 2000.

RECESA. Rede de Capacitação e Extensão Tecnológica em Saneamento Ambiental. Esgotamento sanitário: operação e manutenção de sistemas simplificados de tratamento de esgotos: guia do profissional em treinamento: nível 2. Goiânia: UFG, 2008.

RIBEIRO, H.; GUNTHER, W. M. R.. A integração entre a educação ambiental e o saneamento ambiental como estratégia para a promoção da saúde e do meio ambiente sustentado. São Paulo: 2002.

SÁ, M. C.. Avaliação da qualidade do composto e dos aspectos construtivos e operacionais de banheiros compostáveis. Limeira: 2011.

SOUZA, C. M. N.; FREITAS, C. M.. Discursos de usuários sobre uma intervenção em saneamento: uma análise na ótica da promoção da saúde e da prevenção de doenças. Belém: 2009.

TRATA BRASIL. Instituto Trata Brasil. Benefícios Econômicos da Expansão do Saneamento Brasileiro. São Paulo: Trata Brasil, 2014.

VERGARA, S. C.. Projetos e relatórios de pesquisa em administração. 11 ed. São Paulo: Atlas, 2009.

A CBPC - Companhia Brasileira de Produção Científica (CNPJ: 11.221.422/0001-03) detém os direitos materiais desta publicação. Os direitos referem-se à publicação do trabalho em qualquer parte do mundo, incluindo os direitos às renovações, expansões e disseminações da contribuição, bem como outros direitos subsidiários. Todos os trabalhos publicados eletronicamente poderão posteriormente ser publicados em coletâneas impressas sob coordenação da Sustenere Publishing, da Companhia Brasileira de Produção Científica e seus parceiros autorizados. Os (as) autores (as) preservam os direitos autorais, mas não têm permissão para a publicação da contribuição em outro meio, impresso ou digital, em português ou em tradução. 